\title{
Mário de Andrade, Rachel de Queiroz e Mary Pedrosa cantam para Lorenzo Dow Turner
}

\author{
[ Mário de Andrade, Rachel de Queiroz and Mary \\ Pedrosa sing to Lorenzo Dow Turner
}

\section{Flávia Camargo Toni ${ }^{1}$}

Uma ação combinada entre pesquisadores de universidades do Brasil e dos Estados Unidos recupera para conhecimento e estudo registros fonográficos feitos em I940, no Rio de Janeiro, onde Mário de Andrade, Rachel de Queiroz e Mary Pedrosa cantam seis canções. Entre 2012 e 20I3, Xavier Vatin, professor da Universidade Federal do Recôncavo da Bahia, fez seu pós-doutorado na universidade de Indiana (Bloomington). O musicólogo pesquisava os arquivos de Lorenzo Dow Turner (I890-I972), linguista afro-americano que estudou o dialeto Gullah (estado da Geórgia), visando a refinar seu estudo sobre as heranças culturais africanas em outros países, incluindo o Brasil. $\mathrm{O}$ acervo que pertenceu a Turner guarda os registros feitos durante o segundo semestre de I940, no Rio de Janeiro e na Bahia, tais como as vozes de Menininha do Gantois, Joãozinho da Goméia, Martiniano do Bonfim, Mestre Bimba e outras personalidades importantes da cultura afro-baiana de meados do século passado. Entre rótulos de discos e anotações de campo, Vatin localizara o nome de Mário de Andrade e comunicou o fato ao colega brasileiro Carlos Sandroni, da Universidade Federal de Pernambuco.

Conta o professor Sandroni

Aquela informação me deixou entusiasmado. Eu sabia da existência de um ou dois filmes (sem som) que preservam a imagem em movimento de Mário de Andrade. Evidentemente há imensa quantidade de fotos do escritor. Mas nunca tinha ouvido falar de que houvesse algum registro gravado de sua voz, e muito menos de seu canto. Em várias passagens de sua obra, Mário de Andrade menciona momentos em que cantou, seja com amigos, seja em situações de pesquisa sobre música. Amigos seus mencionam aqui e ali sua voz "de barítono". Além disso, o ano da suposta gravação feita no Rio de Janeiro coincidia com o período em que Mário de Andrade residiu na cidade (entre I938 e I94I).

I Professora Titular e musicóloga do Instituto de Estudos Brasileiros -USP 
O professor Sandroni completa:

Passei então a empenhar esforços para obter uma cópia da gravação evocada naquele dia por Xavier Vatin. Com a intermediação de Darlene Sadlier, professora do Departamento de Português da Universidade de Indiana em Bloomington, e a colaboração de Alan Burdette, diretor dos Archives for Traditional Music da mesma universidade, e de Marylin Graf, arquivista da mesma instituição, a gravação foi localizada. Ilze Akerbergs, dos serviços técnicos da mesma instituição, realizou as cópias digitais dos dois lados de um disco de alumínio da coleção de Lorenzo Turner e as enviou para mim por internet.

De fato, a correspondência de Mário de Andrade e Oneyda Alvarenga ajuda a situar a época da gravação para Lorenzo Dow Turner. Entre 2 de agosto e Io de setembro de I940, o nome do pesquisador norte-americano frequenta as cartas dos musicólogos que discutiam a melhor maneira de realizar as cópias dos discos por ele solicitados, gravações provenientes da expedição da Missão de Pesquisas Folclóricas em I938. A operação era complexa porque os exemplares da Discoteca ainda não possuíam matrizes e eram frágeis para serem enviados para o Rio de Janeiro; por outro lado, o equipamento de gravação de Turner era “[...] um trambolho difícil de viajar pra baixo pra cima.”.

Os registros chegaram em rotação $16 \%$ superior a esta que a partir de agora pode-se ouvir na página do IEB. Os pesquisadores e arquivistas da Universidade de Indiana não poderiam saber que um depoimento de Francisco Mignone, compositor amigo de Mário de Andrade, afirmava ser ele um barítono; os colegas da universidade norte-americana também não poderiam saber que uma das "cantoras" é a escritora Rachel de Queiroz, de quem se tem muitos registros de voz, informações utilizadas pelo musicólogo Fernando Binder para equalizar o som dos registros ora disponíveis na página do IEB (www.ieb.usp.br).

A gravação realizada por Lorenzo Dow Turner é muito nítida, as vozes de cada um dos colaboradores aparece limpa, sem chiados significativos, exceção a uma ou outra palavra onde o volume da gravação não permite distinguir o som sem a intervenção de algum equipamento específico para tanto. Rachel de Queiroz e Mário de Andrade cantam com desenvoltura — ela talvez mais desinibida do que ele —, mas a projeção de voz do musicólogo não esconde o fato de que ele estudara canto no Conservatório Dramático e Musical de São Paulo.

A informação "em letra de forma" data da época em que Oneyda Alvarenga preparou a biografia musical do mestre e amigo a partir dos dados colhidos junto aos arquivos do Conservatório. Ela descobriu que, em I9I4, Mário de Andrade matriculou-se no primeiro ano do Curso de Canto - obtendo, no ano seguinte, nota 9 na disciplina - , mas ao que parece não teria se diplomado porque o Curso tinha a duração de 6 anos3.

2 ALVARENGA, Oneyda \& ANDRADE, Mário de Andrade. Cartas. São Paulo, Duas Cidades, I983, p. 245. (Carta de 2 de agosto de I940)

3 ALVARENGA, Oneyda. Mário de Andrade, um pouco. Rio de Janeiro/São Paulo, José Olympio/SCET, I974, p. 60. 
Tempos depois, Francisco Mignone ajudou a aguçar a curiosidade daqueles que gostariam de ter escutado o poeta e jornalista cantar:

Pouca gente, acredito eu, com os meus 86 anos, ainda existe que conheceu Mário de Andrade músico-cantor. Eu tive essa felicidade. Mário tinha os cursos completos de História da música, estética, acústica, harmonia, piano e... canto. Sim senhor, lembro-me como se fosse hoje de Mário, de opa e círio na mão (vestindo opa, naturalmente) cantando nas procissões em que o coro da velha Igreja de Santa Ifigênia saía às ruas da saudosa Paulicéia... Também estou lembradíssimo de Mário cantando e se acompanhando ao piano uma série de italianizantes modinhas da época. A voz dele era abaritonada e bem afinadinha. Numa feita compareceu em casa de Dona Olívia Guedes Penteado [...], sentou-se ao piano e entoou com entusiasmo as modinhas do passado por ele recolhidas e que conhecemos através de várias edições publicadas até recentemente. Não paravam por aí as atividades de Mário músico. Aluno da classe de piano do compositor João Gomes de Araújo cantou deste uma ária da ópera Carmosina. ${ }^{4}$

Mais conhecido por sua atividade de escritor, poeta, crítico musical e "carteador contumaz", os estudiosos do modernismo não costumam pensar em Mário de Andrade alimentando uma atividade artística no campo da música, ainda que se saiba que foi professor de piano e, ao que parece, professor de dicção, conforme designação de seu contrato profissional. Porém, a prática da música era imprescindível a quem pretendesse estudar as características das linhas melódicas e ritmos brasileiros. Durante a década de I920, com Paulicéia desvairada, Losango cáqui, Primeiro andar e Clã do jaboti já concluídos, editados e distribuídos entre os amigos e críticos, Mário de Andrade começa a se dedicar a outros projetos: queria fazer dois livros didáticos, continuar as pesquisas sobre as constâncias brasileiras na nossa fala e na nossa música. Se dividíssemos a década de 1920 ao meio, poder-se-ia dizer que estes são os afazeres da segunda metade dela e que darão origem à Introdução à estética musical (I926), a Macunaíma (I926/I928), ao Ensaio sobre a música brasileira (I928), ao Compêndio de História da Música (I928), e ao álbum Modinhas Imperiais (I930), para nos atermos aos projetos de maior fôlego.

Para o Ensaio e para o álbum ele não dispõe de material suficiente e solicita aos amigos que enviem melodias coletadas nas diversas regiões onde eles moram, ou que então enviem partituras que eventualmente jogariam fora, porque ele pensa poder aproveitar todos estes dados. No entanto, entre estes mesmos amigos há alguns que se destacam por serem "fontes" de pesquisa ambulantes, caso daqueles que são naturais do Norte, do Nordeste, do Sul ou do Centro Oeste. O interesse pelas cantigas que eles podem cantar para que Mário de Andrade anote aumenta ainda mais quando, em I928, ele é convidado para escrever um trabalho a ser enviado para o Congresso de Arte Popular, em Praga, necessitando, para tanto, matéria para análise e comparação. Este momento pode ser flagrado na correspondência do escritor quando os amigos

4 MIGNONE, Francisco. Saudades do passado. Mário Trezentos, 350. Contra capa de LP. Produzido por Hermínio Bello de Carvalho. Rio de Janeiro, Funarte, I983. 
encaminham suas contribuições, por carta, e é possível ainda saber que eles faziam rodas de cantoria na casa da rua Lopes Chaves.

Dona Gilda de Mello e Souza já mencionara a animação das festas familiares naquele sobradinho quando Mário de Andrade, no papel de anfitrião, sentava-se ao piano para cantar. Nessas ocasiões, os "barulhentos" reuniam-se na sala onde havia o piano de cauda enquanto os demais permaneciam na sala de visitas.

[...] E lembro perfeitamente que Mário se sentava ao piano e, em geral, tocava e cantava quase que o tempo inteiro. O que ele cantava? Ele cantava, que eu me lembro, emboladas, modinhas, muita modinha imperial, e muitos trechos de algumas das coisas que ele tinha recolhido no Nordeste, e que hoje eu sei que seriam, talvez, trechos de saudação do grande cantador Chico Antônio, e nunca música popular, que ele gostava muito de música popular, dessa música urbana e suburbana. Ele gostava demais dessa música, mas não cantava. Ele cantava só isso. ${ }^{5}$

A memória acima se reporta à década de I930, quando Dona Gilda morava na Rua Lopes Chaves. Entretanto, rodas de cantoria não eram apenas festivas: estavam associadas às vezes às pesquisas do musicólogo. A 29 de maio de I936, Antonio Bento de Araújo Lima ${ }^{6}$ escreve para o amigo paulista que então dirigia o Departamento de Cultura e elogia o que ele fizera com uma Nau Catarineta, menção provável a uma festa realizada nos Parques Infantis da Prefeitura. Saudoso ele evocou: "[...] Ultimamente voltei a pensar e a recordar os tempos em que o Nordeste nos musicalizou tão intensamente de modo que a sua carta trouxe uma surpresa muito grata." Ele certamente se refere aos tempos em que ao lado de Mário Pedrosa ${ }^{7}$ cantava cocos e melodias do Rio Grande do Norte e de Pernambuco para estudo, gesto também reproduzido por Luciano Gallet e com a mesma finalidade, uma vez que os dois rapazes frequentemente iam ao Rio de Janeiro. Em torno deles, reuniam-se outros amigos que também conheciam cantigas de outras regiões, fora das capitais de São Paulo e Rio de Janeiro, como as irmãs Elsie, Mary e Celina Houston, Germana Bittencourt e o diplomata Jaime Ovalle.

Entre I926 e I928, Mário de Andrade e Luciano Gallet colecionam melodias para seus estudos e os nomes dos colaboradores do musicólogo são citados nos agradecimentos do Ensaio sobre música brasileira, bem como no ensaio que permaneceu inédito, "A

5 MELLO E SOUZA, Gilda de. Depoimento. In: EU SOU TREZENTOS, eu sou trezentos e cincoenta: Mário de Andrade visto por seus contemporâneos. Rio de Janeiro, Agir, 2008, p. 26.

6 Antonio Bento de Araújo Lima (I902/I988), jornalista e crítico de arte, chegou a residir em São Paulo na década de I920, fixando residência no Rio de Janeiro, onde atuou principalmente junto à imprensa. É na fazenda de propriedade de sua família, a Bom Jardim no Rio Grande do Norte, que Mário de Andrade conhece, em I928, o cantador de cocos Chico Antonio. Foi Araújo Lima quem forneceu a maior parte dos cocos estudados pelo musicólogo no Ensaio sobre música brasileira, dentre os quais O vapor de seu Tertulino fornece a métrica empregada no poema O Coco do Major (Clã do Jabuti, I926).

7 Mário Xavier de Andrade Pedrosa (I900/I98I), pernambucano, também jornalista e crítico de arte, viveu em São Paulo entre I924 e I927, escrevendo para o Diário da Noite. Na década de I940, poucos meses após a gravação para Turner, viaja em exílio para os Estados Unidos. 
literatura dos cocos"'. Destes, um dos mais ativos foi provavelmente o pernambucano Ascenso Ferreira que, apesar de não ser músico, solicitou a colaboração de amigos de Pernambuco para a transcrição das melodias, além de cantar pessoalmente para Mário de Andrade quando esteve em São Paulo, em I926.

Após a publicação do Ensaio sobre música brasileira, em I928, a metodologia de trabalho de Mário de Andrade mudará substancialmente, bem como sua abordagem na análise dos cantos e danças populares. O “divisor de águas” é a viagem ao Norte e Nordeste realizada entre I928 e I929, momento em que seus colaboradores passam a ser os próprios cantadores. A primeira das canções registradas pelo musicólogo no disco de Turner exemplifica o trabalho de campo no interior da Paraíba, quando ele anotou os versos de Deus lhe pague a santa esmola: "Deus li pague a santa esmola/ Deus li leve no andô,/ Acumpanhado di anjo/ Acirculado di flô,/ Assentado à mão direita/ Aos péis di Nosso Sinhô!"

Versos e melodia foram registrados no dia 20 de janeiro de I929, em Catolé do Rocha, e vieram a público — os versos, apenas - pela primeira vez, para os leitores do Diário Nacional de 28 de fevereiro de I929. Dez anos depois, em maio de I939, ou seja, pouco antes de registrar a cantiga de viva voz, ele lembra da situação e da pesquisa na cidade paraibana ao escrever para os leitores do jornal O Estado de S. Paulo?. Antes da crônica de Mário de Andrade, de I929, vale elencar as melodias cantadas pelos colaboradores de Lorenzo Dow Turner, em I940, bem como transcrever a conversa por eles entabulada na segunda face do disco.

\section{O REGISTRO FEITO POR LORENZO DOW TURNER EM I940}

\section{Face A}

A face A do disco de alumínio que foi digitalizado na Universidade de Indiana, com 6 minutos de duração, traz cinco melodias, na ordem a seguir:

I) Aribu, melodia que Rachel de Queiroz aprendera com um palhaço, no Ceará;

2) Zunzum, com Mário de Andrade e Mary (Houston) Pedrosa, peça usada nas rodas de bebida que Mary Pedrosa acreditava ser do final do século XVIII e Mário de Andrade acrescenta ser originária de Minas Gerais;

3) Tava muito doentim [Cantiga da Loetina], cantada por Rachel de Queiroz, colhida por Ascenso Ferreira e Mestre Rosendo, em Pernambuco ${ }^{\text {To; }}$;

8 ANDRADE, Mário de. Os cocos. Prefácio, introdução e notas de Oneyda Alvarenga. São Paulo, Duas Cidades, I982.

9 ANDRADE, Mário de. Catolé do Rocha. O Estado de S. Paulo, ano 9, n. I35, maio, I939, suplemento em rotogravura.

Io Artur Rosendo Pereira, nascido em Maceió e morador do Recife a partir da década de I920, fundador de um terreiro para a tradição Xambá. Ascenso Ferreira (I895/I965), poeta e jornalista, oferece algumas das cantigas estudadas por Mário de Andrade na segunda parte do Ensaio sobre a música brasileira. Em I928, 
4) Deus lhe pague a santa esmola, cantiga de mendigos colhida por Mário de Andrade em Catolé do Rocha, no interior da Paraíba e

5) Toca zumba, cantada por Mário de Andrade, também conhecida como $O$ Bilontra, e composta por Gomes Cardim ${ }^{\mathrm{II}}$.

\section{Face B}

Na face B, com 3 minutos de duração, os cantores - Mary Pedrosa, Rachel de Queiroz e Mário de Andrade - explicam o que gravaram, estimulados por Mário Pedrosa, o qual aparentemente coordena a sessão de trabalho, apesar de que entre as últimas observações as vozes dos "cantadores" se confundam, que deixa escapar algumas observações. O clima é de camaradagem e Rachel de Queiroz, desinibida, canta uma última melodia:

]Mário Pedrosa] — Foram gravadas várias canções. Mário, o que você gravou?

[Mário de Andrade] — Eu gravei uma canção de mendigo colhida por mim mesmo na zona do Catolé do Rocha, no sertão da Paraíba. Os mendigos do Brasil costumam sempre pedir esmolas cantando, principalmente pelo interior. Foi uma destas canções que eu cantei.

[Mário Pedrosa] —E você, Rachel, o que gravou?

[Rachel de Queiroz] - Cantei a princípio o Aribu, uma canção que eu aprendi de um palhaço na minha terra. A outra, a Cantiga da Loetina que pode se chamar o hino nacional recifense. Foi colhida por Ascenso Ferreira com o Major Rosendo em Pernambuco. Mestre Rosendo, aliás, em Pernambuco.

[Mário Pedrosa] — E você, Mary?

[Mary Pedrosa] — Eu não tenho voz, de modo que não tive que gravar coisa alguma, né? Apareço apenas para desafinar um pouquinho no Zum zum que é uma deliciosa cantiga de bebida parece que dos fins do século XVIII.

[Mário de Andrade] — Eu esqueci também de dizer que além da canção de mendigo, como última peça do disco eu cantei ainda o famoso Toca zumba que é um canto dos negros brasileiros do tempo da Abolição.

acolhe o musicólogo paulista quando de sua passagem pelo Recife, bem como auxiliará, em I938, a Missão de Pesquisas Folclóricas do Departamento de Cultura de São Paulo.

II Albert Friedenthal (I862/I92I) reproduz a melodia em versão para canto e piano no sexto volume do Stimmen der Völker in Liedern, Tanzen und Charakterstücken. (Berlim: Schlesinger'sche Buch und Musikhandlung, I9II, p. I7) uma das duas por ele publicadas com o título de O Bilontra e, no caso da cantiga em questão, complementa os dados de colheita: “'Canto e dança dos negros do Brasil', [...] composta por Gomes Cardim pouco após a abolição da escravatura (I888)”. 
Esse canto generalizou-se por todo o Brasil e aliás já está publicado no livro do Friedenthal. Rachel é que podia acrescentar mais alguma coisa ainda sobre o que ela disse quanto as canções de mendigo que ela conhece melhor.

[Rachel de Queiroz] — Realmente eu conheço alguma canção de mendigo variante desta canção que o Mário de Andrade cantou. Por exemplo esta:

\section{— Meu irmão me dê uma esmola. [a escritora canta]}

Essa cantiga é uma invocação a Santa Luzia, padroeira dos cegos, ou inversamente, a padroeira dos videntes.

[Mário Pedrosa] — E sobre o timbre, Mário?

[Mário de Andrade] — Eu acho que quem cantou com maior caráter foi Rachel de Queiroz, a nossa grande romancista cearense. É ela que tem bem o timbre do Nordeste. E todas as nossas canções, quase todas pelo menos cantadas hoje foram do Nordeste, menos o Toca zumba de que não sabemos bem a origem e o Zum zum que Mary Pedrosa cantou e que deve ter vindo de Minas Gerais porque é em Minas Gerais que até hoje se conservam as canções de bebida de depois do jantar.

[Terceiro — Mário Pedrosa?] — Da qual o grande intérprete é o poeta Pedro Nava.

[Mary Pedrosa] — E o meu marido se não canta a canção de brinde, bebe ao jantar e faz jus a todas as honras da canção.

[Mário de Andrade] — Entenda-se, o marido é o outro, é o que perguntou.

[Mary Pedrosa] -É o speaker.

[ Mário Pedrosa? Mário de Andrade?] — Está encerrada a sessão.

\section{Catolé do Rocha ${ }^{12}$}

Cidade de Catolé do Rocha... E são numerosos os nomes evocativos assim. Brejo das Almas, Palmeira dos Índios, Três Corações, e como coroamento dessas denominações maravilhosas de cidades, lá para os limites do Peru, a trágica cidadinha de Remate de Males. Parece que o Brasil guarda o segredo de nomear cidades, pois que positivamente não sei de nomes urbanos, no mundo, mais bonitos que esses. Entramos em pleno

I2 ANDRADE, Mário de. O Turista Aprendiz. Nova edição preparada por Telê Porto Ancona Lopez e Tatiana Longo Figueiredo. São Paulo/Brasília, IEB-USP/IPHAN, no prelo. 
domínio encantado dos romances de capa e espada, Ponson du Terrail, Alexandre Dumas, em que a gente saía completamente bêbado da Taverna do Esqueleto Azul, para ir dormir na Hospedaria do Cavalo de Juno, que nunca teve cavalo.

Foi assim, bêbado de entusiasmo e comoções profundas, em meio a uma seca bem intensa que já obrigava a queimar o xiquexique para alimento das vacas lerdas, encontrando de longe em longe alguma família de retirante pendurada à beira do caminho à espera de condução, foi assim que num dia de sol fachistamente invasor, descendo da serra do Martins, penetrei pelos sertões da Paraíba, e de tardinha achei uma cidade sertaneja.

— Como se chama este lugar?

— Catolé do Rocha, nhor sim.

Uma grande iluminação nos tomou. Eram os domínios pouco antes famosos do barão de Suassuna, terra de coitos, de coiteiros, ninho de cangaço bravo. Nós vínhamos, de resto, já com os nervos arrasados, quase na cola do extinto Lampião. Em Mossoró chegáramos doze dias após o maluco e lírico avanço do bandido sobre a cidade. Em Martins, no alto, ele estivera apenas oito dias antes, e na raiz da serra, num vilejo sem forças, ainda só se falava nele.

Era um domingo e na igrejinha branca, admirável pela harmonia da sua fachada sem torres, a procissão entrava. O céu estava negro de nuvens que não se resolviam a chover sobre a terra, e apenas do lado do poente, uma nesga de céu limpo deixava uns últimos raios de sol focalizarem, para efeitos da fotografia que encima estas evocações, a igreja e as casas da sua direita, no imenso largo vazio. No alto do morro, uma capelinha votiva também gritava muito espevitadamente o seu branco sem poeira, como um defeito de película fotográfica. E as casas coloridas, encarnadas, azuis, verde limão, brincavam, numa esperança de alegria, com o ambiente feroz.

Na igreja entrara toda a religião, talvez toda a bondade do lugar. Do lado de cá da praça, junto às vendolas e mais casas de negócios, estava aglomerada uma outra multidão, que o nosso meio temor do ambiente inda afeiava mais. Um nordestino nosso companheiro interpretava todos aqueles homens lentos e seguros de gesto, que nos examinavam com a maior serenidade fria, sem curiosidade nem carinho, como terríveis cangaceiros cobertos de crimes. $\mathrm{O}$ automóvel fora rodeado com mais interesse que nós, calculado no preço, examinado no brilho e nos detalhes. Provavelmente nenhuma Page inda se aventurara por ali, domínio do Ford.

Quisemos beber água mineral, fugindo à água pardacenta que se bebia naqueles sertões; não havia mais. Pedimos cerveja, guaraná, soda, nada havia, a festa e o leilão tinham acabado com tudo. De um lado, junto a uma lojinha mais propícia, uma velha cantava sentada no chão. Junto dela, num carrinho, estava ajeitada uma paralítica moça, inda por cima, boba. Ria, ria muito, olhando todos, seguindo os que passavam 
com o olhar. A boca aberta deixava escorrer uma baba gosmosa que pendia oscilante, colhendo as últimas luzes do dia. Moscas, moscas brincavam na boca da boba e entravam-lhes pelo colo, que era cheio em seus vinte anos. E a velha a repetir o seu bendito admiravelmente melodioso:

Deus lhe pague a santa esmola!

Deus o leve em seu andor!

Meus companheiros queriam partir, o ambiente angustiava. Pedi-lhes apenas o momento de gravar a melodia em meu livro de notas. E partimos sem que nada houvesse. Alguns tocaram no chapéu, ao que correspondemos com fartura. Quem for a Catolé do Rocha não tema cangaceiros nem se deixe influenciar por ambientes de tempestade. Catolé do Rocha, Palmeira dos Índios, Remate de Males, romances de capa e espada do Brasil.

\section{REFERÊNCIAS BIBLIOGRÁFICAS}

ALVARENGA, Oneyda. Mário de Andrade, um pouco. Rio de Janeiro/São Paulo, José Olympio/SCET, I974. ANDRADE, Mário de. Catolé do Rocha. O Estado de S. Paulo, ano 9, n. I35, maio, I939, suplemento em rotogravura.

ANDRADE, Mário de. Os cocos. Prefácio, introdução e notas de Oneyda Alvarenga. São Paulo, Duas Cidades, I982.

ANDRADE, Mário de. O Turista Aprendiz. Nova edição preparada por Telê Porto Ancona Lopez e Tatiana Longo Figueiredo. São Paulo/Brasília, IEB-USP/IPHAN, no prelo. ALVARENGA, Oneyda \& ANDRADE, Mário de Andrade. Cartas. São Paulo, Duas Cidades, I983. (Carta de 2 de agosto de I940) FRIEDENTHAL, Albert. Stimmen der Völker in Liedern, Tanzen und Charakterstücken. Berlim, Schlesinger'sche Buch und Musikhandlung, I9II.

MELLO E SOUZA, Gilda de. Depoimento. In: EU SOU TREZENTOS, eu sou trezentos e cincoenta: Mário de Andrade visto por seus contemporâneos. Rio de Janeiro, Agir, 2008.

MIGNONE, Francisco. Saudades do passado. Mário Trezentos, 350. Contra capa de LP. Produzido por Hermínio Bello de Carvalho. Rio de Janeiro, Funarte, I983.

DOI: http://dx.doi.org/Io.II6o6/issn.23I6-90IX.voi6Ip239-247 